\title{
Chapter 10 \\ Mobile Technologies for Student Centered Learning in a Distance Higher Education Program
}

\author{
Lisbeth Amhag \\ Malmo University, Sweden
}

\begin{abstract}
The aim of this study is to analyze mobile technologies for student centered learning in a distance higher education program with a focus on mobile online webinars (web-based seminars or conferencing) using mobile applications such as laptops, smart phones, or tablets. As wearable technologies continue to grow it could very well extend to smart glasses, smart watches etc. These tools can provide face-to-face interactions, recording flipped classrooms and parallel chat communications. The data collection consists of observations of ten online face-to-face webinars with 22 students, six interviews, and two surveys. Theoretically, the study joins the research tradition of Computer-Supported Collaborative Learning with emphasis on collaboration, and Computer Self-Efficacy concerned with individuals' media and information literacy. Important conclusions from the study demonstrated mobile interactions increased student centered learning on theoretical concepts, assisted in the ability to review information critically, and provided experiences bridging professional teaching practices.
\end{abstract}

\section{INTRODUCTION}

The aim of this chapter is to analyze and describe wearable technologies for student centered learning in a distance higher education program. We will focus on mobile online webinars using mobile applications such as laptops, tablets or smart phones using teacher-recorded inverted / flipped classrooms. The interactions also include verbal face-to-face (F2F) and parallel textual chat communications with other students and teachers.

DOI: $10.4018 / 978-1-5225-0069-8 . c h 010$ 
Lage et al. (2000) describes the easiest definition of the flipped or inverted classroom: "Inverting the classroom means that events that have traditionally taken place inside the classroom now take place outside the classroom and vice versa" (p.32). The core idea of flipped classrooms are to invert the common instructional approach, as homework before the lesson instead of after, by using teacher-recorded videos with various briefings and interactive instructions. These teacher-recorded instructions and videos can be accessed from different locations by using mobile technologies, such as laptops, tablets or smart phones, prior to the class learning activities. In this study, the flipped classroom consists of two parts: 1) teacher-recorded videos with individual instructions outside the classroom; and 2) interactive group learning activities F2F inside the mobile online webinars. The concept removes the teacher-recorded videos and instructions from the online webinars in order to allow better use of the in-class time during the online webinars F2F with discussions, tutoring and scaffolding student centered learning activities (Bishop \& Verleger, 2013; Lage et al., 2000; Long et al., 2014). Scaffolding knowledge processes is a kind of "thinking types" for fostering expertise in writing and argumentation, designed to provide procedural facilitation (Scardamalia \& Bereiter, 1983).

"Class" becomes the room / place of the mobile online webinars integrating F2F conferencing with a predefined aim of using real-time experiences with guidance from a teacher. The potential of mobile online webinars F2F is that everyone can see and hear each other's verbally through discussions, while at the same time communicating via textual chat and notes. This concept assists learners F2F directly in problem solving, discussing theoretical concepts, reviewing the literature, engaging in collaborative group work, as well evaluations. Furthermore, the synchronous online webinars can be recorded for later asynchronous viewing online within the Learning Management System (LMS) in order to provide students with the opportunity to take a step back, reflect, self-assess and compare various contributions. In summary, several student centered learning activities can be a part of the course structure by using laptops, tablets or smart phones with teacher-recorded videos and instructions before the mobile online webinars F2F and parallel chat communications in order to mediate meaning and learning on a critical and higher-order level.

Examples of learning activities are:

- $\quad$ Tutoring and scaffolding, as well as peer learning processes F2F.

- F2F group discussions regarding theoretical concepts, literature review, authentic experiences, problem solving, and course assignments.

- $\quad$ Receiving and providing F2F peer feedback, co- and self-assessment.

- $\quad$ Collaborate with online chat, common notes, documents and whiteboards F2F.

- $\quad$ Sharing screens and software with others F2F.

- Examinations of course assignments and critical peer review F2F.

It is important to research how and in what ways mobile technologies, as in this study, by using laptops, tablets or smart phones, can support student centered learning and collaboration in a more digitalized higher education, instead of merely focusing on how new media techniques can make education more effective or detrimental (e.g. Amhag, 20011; 2012; 2013; Lee \& Salman, 2012; Rockinson-Szapkiw et al., 2013; Sana et al., 2013). 


\section{BACKGROUND}

Research on the emerging pedagogy of teacher-recorded flipped classroom videos in higher education are mostly based on popular press articles and conference proceedings. Bishop and Verleger (2013) have done a comprehensive survey of flipped classrooms to avoid a considerable amount of buzz in academic circles at all levels. The online buzz the authors have documented from mainly newspaper articles, particularly academically oriented ones, and online blogs. Furthermore, in complete websites dedicated to promoting the flipped classroom ideology. Moreover, several organizations are marketing materials, as screencasts, to help teachers who want to implement the flipped model in their classroom. However, most of the research studies explore student perceptions and work in single-groups, or mixed groups. The results show students overall are generally positive (ibid. 2013). A literature review by Roehl et al. (2013) demonstrates recorded flipped classroom videos are easy-to-use with mobile accessible technologies in order to provide prepared pre-class activities for planned in-class time. This design allows for an expanded range of learner-centered activities during class time and provides opportunities for greater teacher-to-student tutoring, peer-to-peer collaboration and cross-disciplinary engagement.

Likewise, the trial of flipped classroom videos by Wagner et al. (2013) indicate the recorded materials can offer a unique, yet challenging opportunity for universities to collaborate on maximizing the effectiveness of higher education. For example, the effectiveness of lab reinforced materials in comparison to lecture delivered materials and strategies to improve teaching with flipped lectures as a tool to enhance the presentation and retention of lecture materials. Some observations by Wallace (2014) are made regarding evidence on how video, text and instructions are balanced both synchronously and asynchronously according to need and practicality. The roles of the teacher and the student, and how these relationships become more complex and complementary in mobile online spaces, are also changing. The essence of flipped classrooms, according to Long et al. (2014), show more opportunities can be provided to students during in-class time. The teachers can prepare for their course implementing, both the pre-class phase and the in-class phase, applying their own technical literacy, and other available resources and supports. Even faculty contact time can be reduced by two-thirds using an active learning classroom according to Baepler et al. (2014). In this study, the students achieving learning outcomes performed significantly better, in comparison with the traditional classroom. Even student perceptions of the learning environment were improved. These results suggest pedagogically dialogue exchanges and active learning classrooms have a positive influence.

The impact of online synchronous webinars as demonstrated by Nelson's (2010) study, found the learning outcomes of an online synchronous webinar versus classroom instruction among 224 nursing students found no significance difference between the groups. An online synchronous webinar was just as effective as classroom instruction. Rich's (2011) investigation, measuring the impact of online synchronous webinar instruction at a National Science Foundation Advanced Technology Center. The study demonstrated collaborative factors but a lacked additional evidence on actual participation outcomes. Buxton et al. (2012) research evaluated pharmacists' satisfaction with and reasons for enrolling in a series of continuing education webinars. The online F2F webinars included presentations, lectures, workshops and online discussions. The results showed both positive satisfaction for the quality of the program efforts and the method of delivery, but lacked continued participation in subsequent webinars. Using Skype for online communications was examined by Kiriakidis (2010), who found it increased self-efficacy to school and district administrators' and found a gain in students' performance in various centered learning activities. The results showed self-efficacy can be increased through opportunities 
for ongoing, systemic, and logic discussions with other participants. Moreover, institutions of higher education, professional development providers, administrators' associations, school districts, and school leaders may benefit from having an awareness of how mobile online communication software can increase students' self-efficacy in the field of distance teaching and learning. However, all studies above focused on organizing and administrating the education from an individual perspective.

\section{MAIN FOCUS}

In this study, the main focus is on how mobile technologies such as laptops, tablets or smart phones with recorded teacher-created flipped classroom videos and mobile online webinars F2F can support active learning and collaboration in a more digitalized education. The tools are used for students' learning interactions and parallel chat communications with other students and teachers as a rising phenomenon. The following question will be illuminated from the study:

- How and in what way do students collaborate and share knowledge and experiences F2F during mobile online webinars using different multimedia tools in teacher-recorded flipped classroom, textual chat, and note taking as a mediating tool for learning and critical review?

The study monitored 22 student teachers (women=16, men=6) participating in half-time study in the first three continuing web-based courses over a eighteen-month period in Vocational Teacher Education Program, (VTEP). The student teachers were working to become authorized instructors in any of the twelve upper secondary school vocational programs in Sweden. VTEP in Sweden comprises 90 credits. The courses include 60 credits in educational sciences and 30 credits in teacher training at a partner school or within the students own teaching position as unauthorized teacher. The qualitative research design involved an in-depth data collection process and analysis of open-ended interviews and observations of mobile online webinars F2F. As a result, the researcher had the opportunity to obtain a deeper inquiry per individual and collectively in order to provide a more complete understanding. Two surveys' were conducted after completing the second course in June, 2013 and January, 2014 on whether the training contributed to their learning, improved activity engagement, increased their use of rich media and information literacy. Response options were on a 6-point scale: $1=$ Disagree $-6=$ Strongly Agree, and two open-ended qualitative questions.

\section{THEORETICAL APPROACH AND ANALYSIS}

Theoretically, the study joins the research tradition of Computer Supported Collaborative Learning, (CSCL) based on the premise that it is not possible to understand learning solely from individual actions, and Computer Self-Efficacy (CSE) concerned with the individuals' media and information literacy. According to socio-cultural theory, learning always arises as a product of a social community of practice in which our understanding of language, communication, culture, and various aspects of the social context for student learning and development is central. Wenger (1998) considered sociocultural theory of learning in terms of communities of practices constituted by students' negotiated engagement and joint enterprise, as well shared repertoire. There is also a question of collective appropriation of tools 
through language, and how students use language as a tool for learning. Wenger describes assumptions of learning and the nature of knowledge with four premises: 1) we are social beings which is a central aspect of learning, 2) knowledge is a matter of the competence to evaluate, 3) knowing is a matter of participating in the pursuit of such valuation, and 4) meaning is our ability to experience the world and engage with it meaningfully (Wenger 1998. p. 4).

Methodically, the concept of Wenger (1998, p. 5) is divided into four components: 1) meaning is learning as experiences; a way of talking about our abilities, individually and collectively, to experience our life and the world as meaningful, 2) practice is learning as doing; a way of talking about the shared historical and social resources, frameworks, and perspectives to sustain mutual engagement in action, 3) community is learning as belonging; a way of talking about social configurations in which our enterprises are defined as worth pursuing by way of suggesting, and participating as a recognizable competence, and 4) identity is learning as becoming; a way of talking how learning changes the unique person we are and creates personal histories of becoming and development in and between moments of teaching practices and as professionals, e.g. as hairdresser, seller, chef, or vocational teacher. According to this perspective, individual's dialogue, interactions, and interplay constitute a determining factor for the individual's learning and knowledge development in higher vocational education.

The theoretical approach of self-efficacy is related to Computer Self-Efficacy (CSE), which has been used in research concerned with individuals' intentions to use information technology (IT). As in this study, teacher-recorded flipped classroom and participate in mobile online webinars F2F, as well chat. This concept give the opportunities to challenge different efficacies and make assessments of their ability to apply knowledge, and manage and evaluate the peer learning activities, individually and collectively (Bandura, 2002). Bandura stresses "self-precepts of efficacy influence thought patterns, actions, and emotional arousal" (1982, p. 122). Efficacy beliefs shape the students' outcomes, and expectations of their individual performance. Bandura (1984) distinguishes between the component skills in practice, for example the difference between driving a car in freeway traffic and navigating twisting mountain roads. It is comparable with the individual and collective efficacy using the recorded flipped classroom and participating in mobile online webinars F2F, as well the use mobile applications such as laptops, tablets. or smart phones to develop CSE, which can be seen as a level of media and information literacy.

Methodically, CSE has been used through Compeau and Higgins (1995) three interrelated dimensions: magnitude, strength, and generalizability. The magnitude of CSE can be understood as a reflection of the student's cognitive knowledge processes, based on the ability to analyze, communicate, manage information, understand concepts, meta-cognitive skills such as problem solving, interpreting, reflecting and evaluating. The strength of CSE refers to the self-confidence, self-esteem, and students' ability to perform various tasks. Generalizability of CSE reflects the degree online studies are limited to a specific area of a learning activity, such as media and information literacy, using a variety of software for the flipped classroom and computer systems for mobile online webinars F2F with different mobile applications.

\section{IMPLEMENTATION}

The data collection consisted of ten recorded mobile online webinars F2F (10 sessions, 3 hours long), of which five were examinations and the other five were prepared with teacher-recorded flipped classrooms videos during the spring and fall semesters of 2013. The student teachers $(\mathrm{N}=22)$ could also have parallel chat communications during the webinars. The students worked during the three web-based 
courses over an eighteen-month period in the Vocational Teacher Education Program, (VTEP) both individually and in groups with problem-based course assignments with deadlines. They were divided into five groups of four to five students in each. All webinars were scheduled with a date and time for each group and with pre-defined goals and questions from the course literature. During the mobile online webinars F2F students discussed theoretical concepts from the course literature and experiences between teaching practices and professions, as well as tutoring and scaffolding in course assignments. All ten webinars in courses 2 and 3 were recorded and accessible in the learning management system (LMS) in order to provide students with the opportunity to take a step back, reflect, self-assess and compare various contributions. When students were asked if they wanted to participate in the study they signed an agreement. They also got a guideline for the e-meeting system using Adobe Connect and received an online review of the tools (webcam, microphone / headset and chat). A summary of the design during the three courses is given in Table 1.

The data was collected after the three courses were ended. The data was complemented by semistructured research interviews with six students about their participations with other students and teachers. In addition, the researchers wanted feedback on students' use of the teacher-recorded flipped classroom, and the content meaning and dialogue exchanges during the mobile online webinars F2F. Likewise, on the textual chat communications by using the mobile applications such as laptops, tablets, or smart phones. Before the research interviews, all 22 students were asked by email if they wanted to contribute. Six

Table 1. Summary of the design for a flipped classroom using mobile online webinars F2F during three courses in the Vocational Teacher Education Program, (VTEP) (Amhag, 2014)

\begin{tabular}{|c|c|c|}
\hline \multicolumn{2}{|c|}{$\begin{array}{l}\text { Fall semester } 2012 \\
\text { (half-time study) }\end{array}$} & $\begin{array}{l}\text { Course } 1 \text { VTEP - Learning outcome about social relations, conflict management and educational } \\
\text { leadership. Three group wise online webinars as a follow-up of course start and tutoring of course } \\
\text { assignments. }\end{array}$ \\
\hline \multicolumn{2}{|c|}{ Academic year 2013} & (half-time study) \\
\hline Date & Length & Course 2 VTEP - Learning outcome about syllabus, vocational didactics and assessment \\
\hline $02 / 15 / 2013$ & $00: 27: 46$ & Flipped classroom: Theory of Pedagogy \& Didactic, follow-up of course start \\
\hline $02 / 25 / 2013$ & $01: 16: 27$ & Webinar: Teaching \& Education, five groups, drop-in \\
\hline $03 / 15 / 2013$ & $00: 19: 13$ & Flipped classroom: Theory of Formative assessment \\
\hline $03 / 21 / 2013$ & $00: 19: 51$ & Flipped classroom: Theory of Assessment \& Grading \\
\hline $03 / 21 / 2013$ & $01: 14: 01$ & Webinar: Assessment \& Grading, three groups, $25 \mathrm{~min} /$ group \\
\hline $03 / 25 / 2013$ & 01:00:59 & Webinar: Assessment \& Grading, two groups, 30 min / group \\
\hline $05 / 07 / 2013$ & 00:55:06 & Webinar: Tutoring of the two last course assignments, five groups, drop-in \\
\hline Date & Length & Course 3 VTEP - Learning outcome about development, learning and special education \\
\hline $09 / 09 / 2013$ & $00: 28: 05$ & Flipped classroom: Theory of Read \& writing disabilities, follow-up course start \\
\hline $10 / 14 / 2013$ & $00: 47: 49$ & Webinar: Literature of Read \& writing disabilities, five groups, drop-in \\
\hline $10 / 29 / 2013$ & $01: 04: 57$ & Webinar: Examination of Read \& writing disabilities, two groups, $32 \mathrm{~min} /$ group \\
\hline $10 / 31 / 2013$ & $00: 46: 22$ & Webinar: Examination of Read \& writing disabilities, one group \\
\hline $10 / 31 / 2013$ & $00: 42: 36$ & Webinar: Examination of Read \& writing disabilities, one group \\
\hline $10 / 31 / 2013$ & $00: 56: 22$ & Webinar: Examination of Read \& writing disabilities, one group \\
\hline $12 / 10 / 2013$ & $00: 34: 24$ & Flipped classroom: Theory of Teaching \& Education of vocational students \\
\hline $12 / 19 / 2013$ & $00: 39: 50$ & Webinar: Tutoring of the last course assignments, five groups, drop-in \\
\hline
\end{tabular}


students enrolled (including both women and men). The interviews of six students and the whole group of 22 students' dialogue exchanges during ten webinars were transcribed. In the findings we have chosen five excerpts as examples of the analysis by using Wengers (1998) four components; meaning, practice, community and identity, complemented by Compeau and Higgins (1995) three interrelated dimensions: magnitude, strength, and generalizability. These patterns are summarizing the result of the study.

\section{FINDINGS AND ANALYSIS}

The first excerpt addresses student teachers self-efficacy and collaborations with interactions and interplay in mobile online webinars F2F. We examined how it might constitute a determining factor for the students learning and knowledge exchanges at distance.

\section{Student 1}

Student 1, a student in the hairdressing program, describes her experiences of webinars:

Without webinars, I don't think I would have continued to study. In particular, all documents [papers and reports] posted to the LMS and preparations [flipped classroom] before the follow-up webinars, provided a sense of reality. Desire more lectures or other types of tutoring and scaffolding. I also think it has been convenient to be able to participate a little quickly and easily at work [own hairdressing salon] and was able to go away for a while and be with or look through a webinar afterwards. I think it's been good and would have liked additional!

Student 1's statements reflect the importance of social arrangements in the community of practice for meaningful learning at distance (Wenger, 1998). In the web-based learning environment, students can download research articles and reports from the National Agency of Education. The preparations offered teacher-recorded flipped classroom video lectures, prior to the follow-up webinars. Student 1 had developed more of a sense of reality when she managed the information from the literature. Student 1 had low self-efficacy in the beginning of the education program and is reflecting over her meta-cognitive skills. The magnitude of CSE might be gauged in terms of support levels required to undertake tasks (Compeau \& Higgins, 1995). Student 1 felt the webinars helped her ability to continue the VTEP and not to drop out. She desires even more lectures or other component skills in teaching practices. They can be accomplished easier when she goes to work, and reflects on the online webinars afterwards. Like Bandura (1984) distinguishes between the component skills in practice through driving a car, the teacher-recorded flipped classroom videos gave student 1 the ability to negotiate new meanings and further development. The teacher-recorded flipped classroom videos and mobile online webinars F2F involves the whole unique person in a dynamic interplay of participation and reification on learning. A kind of identity in practice because learning constitutes trajectories of participation through connections in and between student 1's past and future in a process of individual and collective learning as becoming (Wenger, 1998, Ch. $3 \& 6$ ). This can be possible when student 1 directly meets other fellow-students and teachers F2F, and discusses how they shall deal with the theoretical concepts from the course literature and experiences between teaching practices and as a working professional. Student 1 has also practiced their teaching experiences within the teacher-recorded flipped classroom as unauthorized teacher: 
I also think the "flipped classroom" is practical to use in my own teaching, a small group of pupils are gathered in the same place. In front of the computer, it is very clear who can or cannot. It quickly becomes a receipt of their understanding or not. Last week I was away from school, and they [the pupils] would find out for their own how to do a task and record and put out what they had done in the LMS. It's a very easy way! It is also a way for those who have difficulty in writing for some reason. They can show what they've done, even if they have not written four pages. They have learned something and can explain with pictures and speech instead.

Student 1's own teaching experiences after three VTEP-courses, highlight the importance of social and practical experiences in higher education in creating new identity through personal histories about becoming in and between one's own teaching practices and profession (Wenger, 1998). The progression of student 1's magnitude of CSE reflects her cognitive knowledge processes to manage digitalized teaching and evaluate the pupils' outcome (Compeau \& Higgins, 1995). The strength of CSE has also advanced. Student 1 has the self-confidence to create new teaching using teacher-recorded flipped classroom and in planning the pupils' tasks in the LMS when she shall be away from school. The pupils can participate in practice together and record their achievement. Student 1 can even score a higher strength of CSE for the content on the computer, and realize how the pupils understood the task of problem solving. Furthermore, student 1 is also talking about her own meaning and learning with teacher-recorded flipped classroom videos and mobile webinars. It was discovered: "It quickly becomes a receipt of their [and own] understanding or not", and how the process can sustain mutual engagement in action (Wenger, 1998). Here student 1 understands what the pupils have done, even if they had not written four page. Instead, they can explain with pictures and speech. The statement provides an echo of student 1's media and information literacy as an achieved level of generalizability of CSE (Compeau \& Higgins, 1995) when using the recorded flipped classroom videos as a teaching tool.

\section{Student 2}

Student 2, a student teacher in Restaurant Management and Food, emphasizes the value of the teacherrecorded flipped classroom videos, but also the importance of the peer assessment processes among pupils at school:

Flipped classroom, I have used most of; I've even let pupils work in groups and record a particular lecture sequence when they were practicing in the dining room. I put up the recorded video sequences for peer feedback. I called the moment "find five errors" and if they could find five errors together, there are often some belongings. I could see the peer feedback was quite different. Pupils must learn how to give peer feedback as well. It is nothing I learned myself automatically, it is also something I have learned and practiced in VTEP.

In this excerpt, Student 2 raises using the teacher-recorded flipped classroom vidoes for group work, as well the possibility of recording the learning activities for peer feedback and self-assessment. Like student 1, her strength of CSE and self-confidence to use the flipped classroom and record lecture sequences for peer feedback has developed (Compeau \& Higgins, 1995). She was aware of the value of peer feedback for learning and what pupils shall focus on when they find five errors together and how creative they must be when they are formulating peer feedback. This formative process does not 
happen automatically or on its own, as student 2 has experienced. It must be practiced in learning as doing (Wenger, 1998). As Wenger states, learning is fundamentally experiential and social, where pupils assist each other. The meaning of meta-cognitive ability is related to a wide range of skills, such as problem solving, communicating, reflecting and evaluating which strengthen the pupils' confidence to work constructively, critically and creatively. It is measured by the extent they use their own and others meaning in their collaboration and dialogue exchanges'.

\section{Student 3}

The mobile education and collaborative learning activities, has also been very important for student 3, a student teacher in the Hotel and Tourism program, as she parallel with VTEP is working halftime as a flight attendant:

The webinars and flipped classroom, I have had huge benefit of! For me it is a bit special because I work as a flight attendant, but also for those students who may want to be able to close the gap for a time. Even the chat communications worked very well in the groups and it was fun with peer feedback and we had some time to respond to the course assignments. I liked it and the peer feedbacks were a great support!

In this excerpt, student 3 highlights the teacher-recorded flipped classroom videos, posted one week before the follow-up online webinars, which were also recorded and accessible afterwards in the learning management system (LMS). These recordings gave good margins for her to take part in the content meaning and discussions afterwards. She also emphasized having a week to provide peer feedback on some classmates' course assignments and their corresponding work in the group's discussion forums in the LMS. The peer assessment processes shaped modes of belonging because learning is a matter of engagement (Wenger, 1998). The students had opportunities to contribute actively to the practice of community with the recorded flipped classroom videos and mobile online webinars, as well textual chat communications, and give and receive peer feedback in the LMS discussion forums. The different software and collaborative learning activities provided value to students.as a degree of generalizability of CSE and media and information literacy (Compeau \& Higgins, 1995). The students also practiced their understanding of the academic way of reading and writing, and making creative use of their higherorder thinking and critical review.

The two last excerpts address how the student teachers experienced the mobile online examination F2F of one course assignment in course 3.

\section{Student 4}

Student 4, a student teacher in the Handicraft program specializing in makeup and skin therapy, is overall positive:

I thought it worked well. Everyone can see and hear each other and ask questions. It is also easier to participate when you do not physically need to participate at the university. I wish more teachers can work in this way, absolutely. It is also the right time to have mobile web-based lectures and presentations online at distance. We as teachers want that too with our pupils at school and give them the possibility to show presentations from home. Then they do not miss anything if they not are at school for some reason. 
In this except, student 4 emphasized the mobile online examination F2F and the importance of using modern technology in a flexible and mobile way in distance higher education and teaching. It is easier to participate from home than at a distance and she wishes more teachers would follow. According to Wenger (1998) it is important that learning involve the interplay between the local, as in this study the students own presentation from home during the examination on the literature about reading and writing disabilities. It provides a kind of global context online when the students can see and hear each other's argumentations from their different practices at distance. Therefore, the locality is connected with creation of learning communities, and depends on a dynamic combination of students' engagement, imagination and alignment to make this interplay between the local and the global to an engine of new learning.

\section{Student 5}

However, some student teachers considered the examination needing to have a clearer structure and teacher leadership. Student 5 points out some dilemmas:

The first participant could speak for ten minutes and then there was not much time left. In addition, the task was already described in detail in text, and archived [in the LMS]. It does not need a presentation of it too. Perhaps it would have been better if we had another issue to discuss, now it was a little cakeon-cake. You cannot say anything new in this little time, there was more to clarify about what you had written. I think that was the idea?

In this excerpt, student 5 raises the issue examinations for learning requires enough structure and continuity to gather students' higher-order thinking and critically review about the literature on reading and writing disabilities (Wenger, 1998). Learning is always a matter of engagement and it depends on the opportunities to contribute actively to the practice of community and to make creative use of each students' respective repertoires. Several researchers stressed academic education should place more value and emphasis on the processes of argumentation engaging in higher-order thinking (e.g. Amhag, 2011; Amhag \& Jakobsson, 2009; Erduran \& Villamanan, 2009; Matusov, 2007; Meyer, 2003; Richardson \& Ice, 2010; Schellens \& Valcke, 2005). This can be seen as "wise thinking" and to some extent "creative thinking" (Craft, 2006), and other forms of reflective interactions supporting students' higher-order thinking and motivation to collaborate in effective ways. Additional studies (e.g. Amhag, 2012; 2013; De Wever, et al., 2009; Dochy, et al., 1999; Scheuer, et al., 2010; Topping, 2005; 2009), have highlighted the fact that students not only need to "learn to argue", they also need to learn good argumentation practices, through argumentations about specific topics. Moreover, they need to use peer learning processes, such as peer assessment, self-assessment and co-assessment.

Some initially problem, showed in the observations who could occur at the start of the education with webinars online, were that the technology of e-meeting arrangements is unreliable. If the mobile connection is too low, the participants are logging out. A feeling of low generalizability of CSE easily arise (Compeau \& Higgins, 1995). It was shown through students constantly were repeating, "Do you hear me?" The access of the voice audio requires a stable mobile connection. Additionally, if the teachers initially are unfamiliar with the technique online and how to support the students. This technical problem pointed especially one of the students out in the interview. 


\section{Two Surveys}

In the two surveys, summarized in Table 2, given to students $(\mathrm{N}=22)$ in June 2013 and January 2014, the student answered the statement: Did the following learning activities contribute to my learning in regards to? a) course start lectures at the university, b) recorded flipped classroom, c) webinars F2F, d) active in webinars, e) seen the flipped classroom, and f) media and information literacy. The result in survey 1 (June, 2013) shows the majority of students (15 answers, 68\%) assumed the flipped classroom (87\%) and webinars (73\%) contributed to their learning, in comparison with campus lectures at the start of the course at $(67 \%)$. However, most of the students had retrospectively reviewed and reflected on the meaning contents of the teacher-recorded flipped classroom videos (80\%). Likewise, the majority of the students considered they had been active during the webinars (80\%) by discussing different perspectives. All students feel they need to have media and information literacy (100\% strongly agree).

In the second survey, after the third course (January 2014), the majority of the students (12 answers, $55 \%$ ) assumed the lectures at the start of the course (92\%) contributed to their learning, the webinars (75\%), and a little fewer for the recorded flipped classroom (66\%). However, all students had retrospectively reviewed and reflected on the meaning contents of the recorded flipped classroom videos (92\%). Likewise, the majority of students' considered they were active during the webinars (83\%) by discussing different perspectives. All students feel they need to have media and information literacy (100\% strongly agree). In the open-ended questions, some students required even more knowledge exchanges and interactive collaborations for learning and development.

In summary, the two surveys shows that all students $(\mathrm{N}=22)$ assumed they had generalizability of CSE [13] limited to this situated area at distance to use different software such as recorded flipped classroom videos and mobile online webinars F2F with parallel chat communications which shapes their media and information literacy. The majority of the students' show also strength of CSE through their self-confidence and self-esteem to take advantage of the recorded flipped classroom videos and thus be able to be more active in the online webinars F2F and perform various tasks in VTEP on an higher academic level.

Table 2. Two surveys results from June 2013 and January 2014 on: Did the following learning activities contribute to my learning? (Amhag, 2014)

\begin{tabular}{|l|c|c|c|c|}
\hline \multicolumn{1}{|c|}{ Learning Activities } & $\begin{array}{c}\text { Survey 1 (68\%) } \\
\text { 1-3 Disagree- Partly } \\
\text { Agree }\end{array}$ & $\begin{array}{c}\text { Survey 1 (68\%) } \\
\text { 4-6 Agree - Strongly } \\
\text { Agree }\end{array}$ & $\begin{array}{c}\text { Survey 2 (55\%) } \\
\text { 1-3 Disagree- Partly } \\
\text { Agree }\end{array}$ & $\begin{array}{c}\text { Survey 2 (55\%) } \\
\text { 4-6 Agree - Strongly } \\
\text { Agree }\end{array}$ \\
\hline $\begin{array}{l}\text { University lectures at course } \\
\text { start }\end{array}$ & $33 \%$ & $67 \%$ & $8 \%$ & $92 \%$ \\
\hline Flipped classroom & $13 \%$ & $87 \%$ & $34 \%$ & $66 \%$ \\
\hline Webinars F2F & $27 \%$ & $73 \%$ & $25 \%$ & $75 \%$ \\
\hline Active in webinars & $20 \%$ & $80 \%$ & $17 \%$ & $83 \%$ \\
\hline Seen flipped classroom & $20 \%$ & $80 \%$ & $8 \%$ & $92 \%$ \\
\hline Media \& information literacy & $0 \%$ & $100 \%$ & $0 \%$ & $100 \%$ \\
\hline
\end{tabular}




\section{SOLUTIONS AND RECOMMENDATIONS}

Important conclusions from the results of the learning activities with teacher-recorded flipped classroom videos using mobile online webinars F2F, and textual chat communications are the time and space for learning and development expands. The teacher-recorded flipped classroom gave students more learnercentered experiences when they had the ability to prepare and negotiate new meanings with support from the teacher-recorded flipped classroom videos before and during mobile online webinars F2F by using laptops, tablets or smart phone for further learning and collaboration. The same results are shown in the research review on recorded flipped classroom videos by Bishop and Verleger (2013). In another study by Long et al. (2014) demonstrates students are generally positive to the working methods because it offers more preparation for the course content to support them complete the assignments and feel more prepared for scientific reading, academic writing, presentations, and examinations. The same results also appear in a study by Beapler et al. (2014) demonstrating students feel more learner-centered education when they are teaching in recorded flipped classroom videos, rather than traditional forms of monological lectures in a university classroom.

Fulton (2012) argues for a new way of teaching and learning, and has listed seven benefits of teacherrecorded flipped classroom videos: (1) students can work at their own speed, (2) homework before scheduled lectures provides teachers with better insight into students' reading and writing abilities, as well different learning styles, (3) teachers can more easily assume the learning outcomes and give feedback, (4) teaching time is used more efficiently and creatively, (5) the students' interest and involvement increases, contributing to better learning outcomes and development, (6) learning theories support new methods, and (7) the use of wearable technologies provide increased flexibility.

Although, the study of Herreid and Schiller (2013) among 200 teachers suggest that teacher-recorded flipped classroom videos brings more: a) discussions with and between students about the authentic problems, b) research-based work, c) those who miss teaching occasions can take part of in recorded flipped classroom videos and webinars retrospectively, d) the method promotes the design of in-class time and out-of-class time; e) students are more active and take more responsibility for their learning, and f) the students appreciate the working methods. Another study by Beapler et al. (2014) show the benefits in student grades were significantly better if they had blended learning, as with online webinars and recorded flipped classroom videos, combined with traditional seminars and lectures at the university, compared with a group using traditional teaching and individual tests in the classroom. The research review by Roehl et al. (2013) shows the technology in recordings of the recorded flipped classroom videos were perceived as easy to use by teachers. Likewise, observations by Wallace (2013) concerning the manner in which videos and text between synchronous and asynchronous media are used in teaching, shows how teachers and students relationships changed. They became more complex and complementary when teaching online based on the participants' conditions, needs and media literacy.

\section{CONCLUSION}

The design of distance teaching in higher education for students learner centered teaching can be considered an updated version of the "knowledge-building environments for progressive discourse" stated by Scardamalia and Bereiter (1994, p. 37-38). The integration and implementation of teacher-recorded flipped classroom videos and mobile online webinars F2F by using mobile technologies could also 
extend to smart glasses, smart watches, or other new devices. Twenty years ago, Scardamalia and Bereiter $(1993 ; 1994)$ argued various programs and courses must integrate and implement e-mail, bulletin boards and presentation material more thoroughly in the education. They also pointed to the importance for students to see themselves as active knowledge builders, not as passive recipients. Moreover, it is essential for students to be able to identify their own knowledge needs, to recognize what is unclear, confusing, doubtful, incoherent, and so on. The role of the teacher is to give feed up, feedback and feed forward (Amhag, 2011, 2012; 2013), and show commitment to increasing the students' learning and development. In the modern design of learner-centered teaching at distance in higher education program, the teachers should include the following collaborative learning activities:

- $\quad$ Recorded flipped classroom videos before follow-up webinars F2F.

- Webinars F2F with group discussions on course content, literature, theories, concepts, problem solving and exchanges of knowledge and experiences.

- Tutoring and scaffolding F2F in scientific reading and academic writing, as well media and information literacy.

- $\quad$ Peer feedback, co- and self-assessment and critical review of their own and other's work.

- $\quad$ Collaboration with shared whiteboard, notes, and documents F2F.

- $\quad$ Split screen and software used with others F2F.

- Examinations online F2F of some course assignments.

These actions can be compared with "into an ongoing stream of activity", involving explicit and implicit "stimulus means" (Wertsch, 2007, pp. 180-184). They are explicit through tutoring, scaffolding through teacher-recorded flipped classroom videos or sharing other students' expertise and experiences directly during mobile online webinars F2F and textual chat communication. Opposed to implicit through inner reflection and uncovering thoughts which are tending to be hidden and non-transitory and therefore, more difficult to detect.

\section{REFERENCES}

Amhag, L. (2011). Students'Argument Patterns in Asynchronous Dialogues for Learning.

Amhag, L. (2012). High school students' argument patterns in online peer feedback. E. Favaron, P. M. Pumilia-Gnarini, E. Pacetti, J. Bishop \& L. Guerra (Ed.), Handbook of Research on Didactic Strategies and Technologies for Education: Incorporating Advancements (Vol. 2, Ch. 62, pp. 711-723). Retrieved from http://www.igi-global.com/chapter/high-school-students-argument- patterns/72113

Amhag, L. (2013). Creativity in and between Collaborative Peer Assessment Processes in Higher Distance Education. In Creative Education (pp. 94-104). Special Issue on Higher Education; doi:10.4236/ ce.2013.47A2011

Amhag, L., \& Jakobsson, A. (2009). Collaborative Learning as a Collective Competence when Students Use the Potential of Meaning in Asynchronous Dialogues. Computers \& Education, 52(3), 656-667. doi:10.1016/j.compedu.2008.11.012 
Baepler, P., Walker, J. D., \& Driessen, M. (2014). It's not about seat time: Blending, flipping, and efficiency in active learning classrooms. Computers \& Education, 78, 227-236. doi:10.1016/j.compedu.2014.06.006

Bandura, A. (1984). Recycling Misconceptions of Perceived Self-efficacy. Cognitive Therapy and Research, 8(3), 231-255. doi:10.1007/BF01172995

Bandura, A. (2002). Growing primacy of human agency in adaption and change in the electronic era. European Psychologist, 7(1), 2-16. doi:10.1027//1016-9040.7.1.2

Bishop, J. L., \& Verleger, M. A. (2013). The Flipped Classroom: A Survey of the Research. Paper presented at the 120th ASEE Conference \& Exposition.

Buxton, E. C., Burns, E. C., \& De Muth, J. E. (2012). Instructional Design and Assessment. Professional Development Webinars for Pharmacists. American Journal of Pharmaceutical Education, 76(8), 1-7. doi:10.5688/ajpe768155 PMID:23129854

Compeau, D. R., \& Higgins, C. A. (1995). Computer self-efficacy: Development of measure and initial test. Management Information Systems Quarterly, 19(2), 189-211. doi:10.2307/249688

Craft, A. (2006). Fostering creativity with wisdom. Cambridge Journal of Education, 36(3), 337-350. doi:10.1080/03057640600865835

De Wever, B., Van Keer, H., Schellens, T., \& Valcke, M. (2009). Structuring asynchronous discussion groups: The impact of role assignment and self-assessment on students' levels of knowledge construction through social negotiation. Journal of Computer Assisted Learning, 25(2), 177-188. doi:10.1111/j.13652729.2008.00292.x

Dochy, F., Segers, M., \& Sluijsmans, D. (1999). The use of self-, peer- and co-assessment in higher education: A review. Studies in Higher Education, 24(3), 331-350. doi:10.1080/03075079912331379935

Erduran, S. \& Villamanan, R. (2009). Cool Argument: Engineering Students`'Written Arguments about Thermodynamics in the Context of the Peltier Effect in Refrigeration. Educacaión quimica (pp. 119-125).

Fulton, K. (2012). Upside down and inside out: Flip your classroom to improve student learning. Learning and Leading with Technology, 39(8), 12-17.

Herreid, C. F., \& Schiller, N. A. (2013). Case studies and the flipped classroom. Journal of College Science Teaching, 42(5), 62-66.

Kiriakidis, P. (2010). How Does Skype, as an Online Communication Software Tool, Contribute to K-12 Administrators' Level of Self-efficacy? International Journal of Leadership in Educational Technology, 1(9), 1-29.

Lage, M. J., Platt, G. J., \& Treglia, M. (2000). Inverting the classroom: A gateway to creating an inclusive learning environment. The Journal of Economic Education, 31(1),30-43. doi:10.1080/00220480009596759

Lee, K., \& Salman, R. (2012). The Design and Development of Mobile Collaborative Learning Application Using Android. Journal of Information Technology and Application in Education, 1(1), 1-8. 
Long, T., Logan, J., \& Waugh, M. (2014). Students' Perceptions of Pre-class Instructional Video in the Flipped Classroom Model: A Survey Study. Proceedings of Society for Information Technology \& Teacher Education International Conference. VA: AACE.

Matusov, E. (2007). Applying Bakhtin Scholarship on Discourse in Education: A Critical Review Essay. Educational Theory, 57(2), 215-237. doi:10.1111/j.1741-5446.2007.00253.x

Meyer, K. (2003). Face-to-face versus threaded discussions: The role of time and higher-order thinking. Journal of Asynchronous Learning Networks, 7(3), 55-65.

Research Highlights in Technology and Teacher Education. (2011). Ed/ITLib Digital Library. Retrieved from http://storefront.acculink.com/aace

Rich, R. L. (2011). A framework for synchronous web-based professional development [Thesis]. Stockton, California.

Richardson, J. C., \& Ice, P. (2010). Investigating students' level of critical thinking across instructional strategies in online discussions. The Internet and Higher Education, 13(1-2), 52-59. doi:10.1016/j. iheduc.2009.10.009

Rockinson-Szapkiw, A. J., Courduff, J., Carter, K., \& Bennett, D. (2013). Electronic versus traditional print textbooks: A comparison study on the influence of university students' learning. Computers \& Education, 63, 259-266. doi:10.1016/j.compedu.2012.11.022

Roehl, A., Reddy, S. L., \& Shannon, G. J. (2013). The Flipped Classroom: An Opportunity to Engage Millennial Students through Active Learning Strategies. Journal of Family and Consumer Sciences, 105(2), 44-49. doi:10.14307/JFCS105.2.12

Sana, F., Weston, T., \& Cepeda, N. J. (2013). Laptop multitasking hinders classroom learning for both users and nearby peers. Computers \& Education, 62, 24-31. doi:10.1016/j.compedu.2012.10.003

Scardamalia, M., \& Bereiter, C. (1993). Technologies for knowledge-building discourse. Communications of the ACM, 36(5), 37-41. doi:10.1145/155049.155056

Scardamalia, M., \& Bereiter, C. (1994). Computer support for knowledge-building communities. Journal of the Learning Sciences, 3(3), 265-283. doi:10.1207/s15327809jls0303_3

Schellens, T., \& Valcke, M. (2005). Collaborative learning in asynchronous discussion groups: What about the impact on cognitive processing? Computers in Human Behavior, 21(6), 957-975. doi:10.1016/j. chb.2004.02.025

Scheuer, O., Loll, F., Pinkwart, N., \& McLaren, B. M. (2010). Computer-supported argumentation: A review of the state of the art. Computer-Supported Collaborative Learning, 5(5), 43-102. doi:10.1007/ s11412-009-9080-x

Topping, K. (1998). Peer Assessment between Students in Colleges and Universities. Review of Educational Research, 68(3), 249-276. doi:10.3102/00346543068003249

Topping, K. (2005). Trends in Peer Learning. Educational Psychology, 25(6), 631-645. doi:10.1080/01443410500345172 
Wagner, D., Laforge, P., \& Cripps, D. (2013). Lecture Material Retention: a First Trial Report on Flipped Classroom Strategies in Electronic Systems Engineering at the University of Regina. Paper presented at the Canadian Engineering Education Association Conference, Montreal, Canada.

Wallace, A. (2014). Social Learning Platforms and the Flipped Classroom. International Journal of Information and Education Technology, 4(4), 293-296. doi:10.7763/IJIET.2014.V4.416

Wenger, E. (1998). Communities of Practice - Learning, Meaning, and Identity. New York: Cambridge University Press. doi:10.1017/CBO9780511803932

Wertsch, J. V. (2007). Mediation. In H. Daniels, M. Cole, \& J. V. Wertsch(Eds.), The Cambridge Companion to Vygotsky (pp. 178-192). Cambridge: Cambridge University Press. doi:10.1017/CCOL0521831040.008

\section{KEY TERMS AND DEFINITIONS}

Computer Self-Efficacy (CSE): Is concerned with individuals' intentions to use information technology (IT) and the opportunities to challenge different efficacy beliefs, e.g. shape the students' outcomes, and expectations of their individual performance.

Computer-Supported Collaborative Learning (CSCL): Is the field concerned with how information and communication technology (ICT) might support collaborative learning in groups.

Distance Education: A specific context of education at distance depending on whether the teaching takes place synchronously in the same space and time, e.g. web-based seminars or conferencing, or asynchronously in different time and space, e.g. in text-based discussion forums and chat communications.

Distance Learning: Involves different learning activities at distance, e.g. peer assessment, give and receive peer feedback, critically review literature and each other's work, as well self-assess their efforts, regardless of time and space.

Flipped Classroom: Is inverting the common instructional approach by using teacher-recorded videos with various briefings and interactive instructions accessed from different locations using mobile technologies prior to the class learning activities.

Mobile Applications: Is also called mobile apps, by using Internet applications that run on laptops, tablets and smartphones or other mobile devices.

Online Webinar: Short for online web-based seminar or conferencing where group of students and their teacher have presentations, lectures, workshops or seminars face-to-face that is transmitted over the Web.

Wearable Technology: Refers to computer-powered devices or equipment that can be worn by a user, such as laptop, smart phone, tablet, smart watches, smart glasses, or similar items that have functions for to take photos and sync with your mobile devices. 